\title{
Analysis of the ENSO Signal in Tropospheric and Stratospheric Temperatures Observed by MSU, 1979-2000
}

\author{
Natalia Calvo Fernández, ${ }^{*}$ Rolando R. García, ${ }^{+}$Ricardo García Herrera,* \\ David Gallego Puyol,* Luis Gimeno Presa, @ Emiliano Hernández Martín,* \\ AND PEDRO RIBERA RodrígueZ \& \\ *Universidad Complutense de Madrid, Madrid, Spain \\ ${ }^{+}$National Center for Atmospheric Research, ${ }^{\#}$ Boulder, Colorado \\ ${ }^{\circledR}$ Universidad de Vigo, Orense, Spain \\ ${ }^{\&}$ Universidad Pablo de Olavide, Seville, Spain
}

(Manuscript received 14 August 2003, in final form 3 March 2004)

\begin{abstract}
The El Niño-Southern Oscillation (ENSO) signal in the troposphere and lower stratosphere was investigated using Microwave Sounding Unit (MSU) data for the period 1979-2000. Empirical orthogonal functions (EOFs) were computed separately for zonal-mean and eddy temperatures in the Tropics and shown to provide a compact, physically intuitive description of ENSO that captures many of the details of its inception and evolution. Regressions of the MSU data on the principal components (PCs) of the tropical EOFs were then used to estimate the global signal of ENSO. The results show that ENSO accounts for over two-thirds of the temperature variability in the tropical troposphere, where its signature is composed of distinct zonal-mean and eddy patterns whose evolution is not simultaneous. In the tropical stratosphere, and outside the Tropics, ENSO explains a much smaller fraction of the variance $(\sim 10 \%)$, and manifests itself purely in the form of eddy anomaly patterns. The PCs of the eddy EOFs of the tropical stratosphere are almost perfectly correlated with those of the troposphere, suggesting that together the EOFs describe the vertical structure of equatorial waves. Volcanic eruptions and the quasi-biennial oscillation $(\mathrm{QBO})$ are responsible for most of the variability $(\sim 87 \%)$ of the tropical lower stratosphere, and this variability is uncorrelated with ENSO; in the tropical troposphere, the effect of volcanic eruptions is detectable but small, accounting for about $3 \%$ of the variance.
\end{abstract}

\section{Introduction}

Numerous studies over the last two decades have analyzed the influence of El Niño-Southern Oscillation (ENSO) events on atmospheric temperature. This work has typically focused on two aspects of the phenomenon: the lag between the response of the tropical atmosphere and ENSO (the latter being characterized by a pressure or sea surface temperature index), and the geographical distribution of ENSO-related temperature anomalies. Most authors have found that maximum correlations between ENSO indices and temperature occur at a lag of one or two seasons (Angell 1981, 2000a; Jones 1989; Christy and McNider 1994; Yulaeva and Wallace 1994; Trenberth et al. 2002), although the precise results depend on the dataset used in the analysis.

\footnotetext{
\# The National Center for Atmospheric Research is sponsored by the National Science Foundation.
}

Corresponding author address: Rolando R. García, National Center for Atmospheric Research, P.O. Box 3000, Boulder, CO 803073000.

E-mail: rgarcia@ucar.edu
As regards spatial distribution, the ENSO signal in surface temperature is characterized by warming over the central and eastern Pacific, in most of the Indian Ocean, and in southeast Africa in association with the warm phase of ENSO (Kiladis and Diaz 1989; Halpert and Ropelewski 1992; Trenberth and Caron 2000; Diaz et al. 2001; Trenberth et al. 2002).

In the lower stratosphere, several authors have studied the signal of ENSO in geopotential height to elucidate its effects on the extratropical stratospheric circulation (Wallace and Chang 1982; van Loon and Labitzke 1987; Hamilton 1993; Baldwin and O'Sullivan 1995). Although the effect of ENSO on tropical lower-stratospheric temperatures has not been documented as widely as its effect on surface or tropospheric temperatures, the studies of Reid et al. (1989), and Yulaeva and Wallace (1994) indicate that a transition from positive to negative correlations with ENSO occurs around the tropopause.

Most of the studies cited earlier have used linear regression, composites, and cross-correlation analysis to study the ENSO signal in the atmosphere. In the last decade analyses in terms of empirical orthogonal func- 
tions (EOFs) have been carried out, providing an alternative means of characterizing the ENSO signal. For example, Kelly and Jones (1996) analyzed surface air temperatures and found two dominant EOFs associated with the ENSO signal, the temporal evolution of the second EOF leading that of the first. Similarly, Yulaeva and Wallace (1994) applied EOF analysis to microwave sounding unit (MSU) observations of tropospheric air temperatures for 1979-91, and found a zonal-mean pattern and a "residual" signature (obtained by subtracting the tropical mean temperature) that leads the former by around 3 months.

In the present study, we analyze the ENSO temperature signal in the middle troposphere and in the lower stratosphere. We use temperature data from the series of MSU instruments that have been carried on board National Oceanic and Atmospheric Administration (NOAA) polar-orbiting satellites since 1979. Several authors (Spencer and Christy 1993; Hurrell et al. 2000; Angell 2000a) have compared MSU observations for the period 1979-98 with data from the global radiosonde network and shown that they exhibit generally good agreement. While MSU observations cannot match the vertical resolution of radiosondes, they have the important advantage of providing homogeneous global coverage, which makes them especially well suited for studying the spatial patterns of ENSO anomalies.

The suitability of MSU for studying the global signal of ENSO was demonstrated by the work of Yulaeva and Wallace (1994, hereafter YW94). Here we analyze data from MSU channels 2LT and 4 over the longer period 1979-2000, which includes the strong ENSO events of the 1990s, and we document the ENSO signal in both the Tropics and at extratropical latitudes. To produce a more physically meaningful description of ENSO in the Tropics, we apply EOF analysis separately to the zonalmean temperature field and to the deviations from the zonal mean; to characterize the behavior at extratropical latitudes, we employ multiple regression onto the principal components of the tropical EOFs. We show that this approach results in a compact, physically intuitive representation of atmospheric variability that provides quantitative estimates of the variance of the temperature field associated with ENSO, as well as with other phenomena. This methodology follows the work of YW94 in several important respects, but addresses the problem of defining EOFs and establishing connections with extratropical behavior in what is perhaps a more systematic fashion.

\section{Data and method}

Monthly mean MSU observations have been used to characterize atmospheric temperatures. The MSU radiometers measure the intensity of the molecular oxygen emissions near the $60-\mathrm{GHz}$ absorption band, which is directly proportional to air temperature. MSU observes the radiation emitted at different frequencies, which originates from different atmospheric layers. Thus, channel $2(53.74 \mathrm{GHz})$ responds to temperatures (T2) in a layer centered at about $7 \mathrm{~km}$. The bulk of this radiation originates in the troposphere, although a small but nonnegligible part emanates from the lower stratosphere. To reduce the influence of the upper troposphere and stratosphere, MSU channel 2 observations from different viewing angles are arithmetically combined to form a new channel (T2LT) that measures lower-tropospheric temperature centered at about 4-km altitude and minimizes stratospheric contributions (Christy et al. 2000). MSU channel 4, at 57.95 MHz, is used to monitor the temperature (T4) of the lower stratosphere (Spencer and Christy 1993; Christy and Drouilhet 1994). MSU data are available on a global $2.5^{\circ} \times 2.5^{\circ}$ grid from 1979 onward. In this study, we use monthly mean T2LT and T4 data (version d) for the period January 1979 through December 2000 (available online at http:// vortex.nsstc.uah.edu/data/msu). This version accounts for the effects of orbit decay and drift, variations in the instrument body temperature, and calibration errors.

The intensity of ENSO events can be represented by several well-known tropical Pacific sea surface temperature (SST) indices available from the Climate Prediction Center of NOAA (see www.cpc.noaa.gov/data/ indices). A preliminary analysis (not shown) indicated that the most consistent ocean-atmosphere relationship, when MSU temperatures are used, is found for Niño3.4 ( $\mathrm{N} 3.4$; between $5^{\circ} \mathrm{S}-5^{\circ} \mathrm{N}$ latitude and $120^{\circ}-170^{\circ} \mathrm{W}$ longitude). This index will be used exclusively in the paper.

We analyzed the monthly mean T2LT and T4 MSU temperature series by means of empirical orthogonal functions (Richman 1986; von Storch and Zwiers 1999). The data were pretreated to eliminate the annual cycle, remove linear trends, and smooth short-period fluctuations (2-3 months), the last being accomplished by applying a 1-2-1 filter at every grid point. We then performed a conventional decomposition into EOFs after weighting the data with the following function of latitude, $\theta$,

$$
f(\theta)=\frac{1}{2}\left[1+\tanh \left(-\frac{|\theta|-25^{\circ}}{5^{\circ}}\right)\right],
$$

which suppresses variability outside the Tropics. When the data are treated in this fashion, a large fraction of tropical variability can be described by a few EOFs whose principal components (PCs) are strongly correlated with N3.4. This is not the case if unweighted data are used, presumably because much of the extratropical variance is associated with processes that behave stochastically and independently of ENSO. Extratropical variance associated with ENSO can then be captured by regressing the MSU data onto the $\mathrm{PC}$ series, as will be shown in section 4 .

In order to distinguish between zonally symmetric and asymmetric variability, it also proved useful to de- 


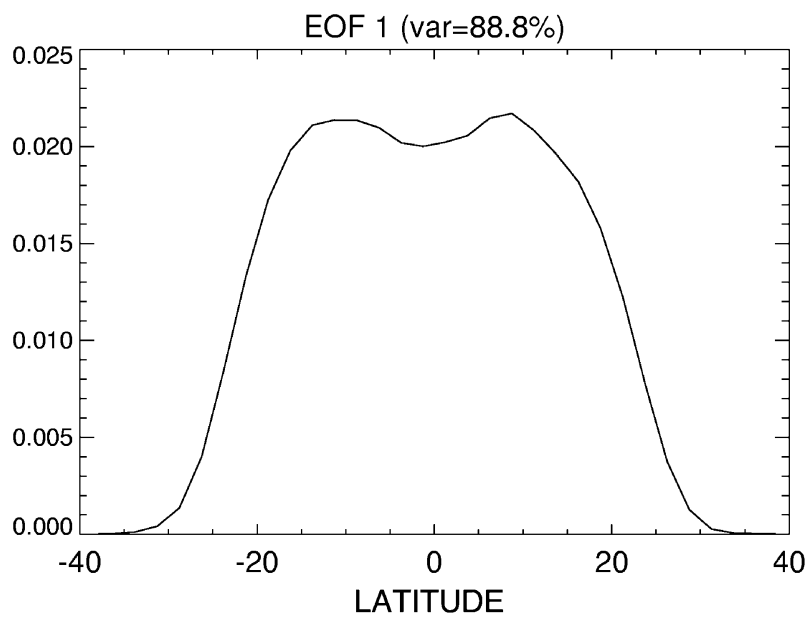

FIG. 1. First EOF of MSU T2LT zonal-mean temperature in the Tropics. Before calculating the EOF, the data have been windowed with the function defined by Eq. (1) and zonally averaged. The amplitude scale is arbitrary.

compose the MSU temperature field into zonal-mean $[T]$ and eddy components $T^{*}$,

$$
T=[T]+T^{*},
$$

and apply EOF analysis to each component separately. It will be seen below that this yields a clearer representation of ENSO, especially as regards the time lags between the N3.4 index and the zonally symmetric and asymmetric EOFs. In this paper, we denote zonal-mean terms with square brackets [] and eddy terms with an asterisk *.

\section{The ENSO signal in the Tropics \\ a. The tropical troposphere}

The first EOF of the tropospheric zonal-mean temperature field, [EOF1], is shown in Fig. 1. It accounts for a very large fraction (89\%) of the zonal-mean variance, which itself represents $56 \%$ of the total (see Table 1 for a summary of the distribution of MSU T2LT tropical variance). Its PC series, shown in Fig. 2, is highly correlated $^{1}$ with $\mathrm{N} 3.4$, with the maximum occurring at a lag of about 4 months. YW94 also calculated a zonalmean EOF (using global MSU T2 data for 1979-91 weighted by the cosine of latitude), whose structure in the Tropics is similar to our [EOF1]. In addition, lagged behavior with respect to N3.4 has been documented for tropical-mean temperatures (Angell 1981, 2000b; Jones 1989; Trenberth et al. 2002). Thus, a signal that encompasses the Tropics and lags N3.4 by several months is a robust aspect of ENSO-related variability.

\footnotetext{
${ }^{1}$ The significance of this and other correlations has been evaluated by applying Student's $t$ test at the 95\% confidence level. Autocorrelation effects have been treated by reducing the number of degrees of freedom according to the level of autocorrelation of the series in question (see Oort and Yienger 1996).
}

TABLE 1. Distribution of MSU T2LT variance in the Tropics.

\begin{tabular}{lccc}
\hline \hline & $\begin{array}{c}\text { Zonal-mean } T \\
(\%)\end{array}$ & Eddy $T(\%)$ & Total $T(\%)$ \\
\hline Zonal mean $^{\text {[EOF1] }}$ & 100 & - & 56 \\
[EOF2] $_{\text {Eddies }}$ & 89 & - & $50^{\mathrm{a}}$ \\
EOF1 $^{*}$ & 6 & - & 3 \\
EOF2 $^{*}$ & - & 100 & 44 \\
& - & 31 & $14^{\mathrm{a}}$ \\
\hline
\end{tabular}

${ }^{a}$ EOFs and variance associated with ENSO.

Figure 3 shows the first two EOFs of the eddy temperature field, $\mathrm{EOF} 1 *$ and $\mathrm{EOF} 2 *$, which together account for over $40 \%$ of the zonally asymmetric variance in the tropical troposphere. EOF1* explains over $31 \%$ of this variability, and evidently represents the wavelike anomalies forced by the warming of eastern Pacific SSTs; it is analogous to the residual tropical EOF obtained by YW94 after subtracting the tropical-mean temperature averaged between $\pm 20^{\circ}$. The PC of EOF1* (Fig. 4a) is very well correlated with N3.4 $(r=0.89$ at zero lag). On the other hand, the PC of EOF2* leads N3.4 by $10-12$ months (Fig. 4b), suggesting that it is related to the incipient phase of ENSO events; indeed, $\mathrm{EOF} 2 *$ is reminiscent of the surface wind anomaly pattern near the date line documented by Rasmusson and Carpenter (1982, their Fig. 18) for the "onset" stage of
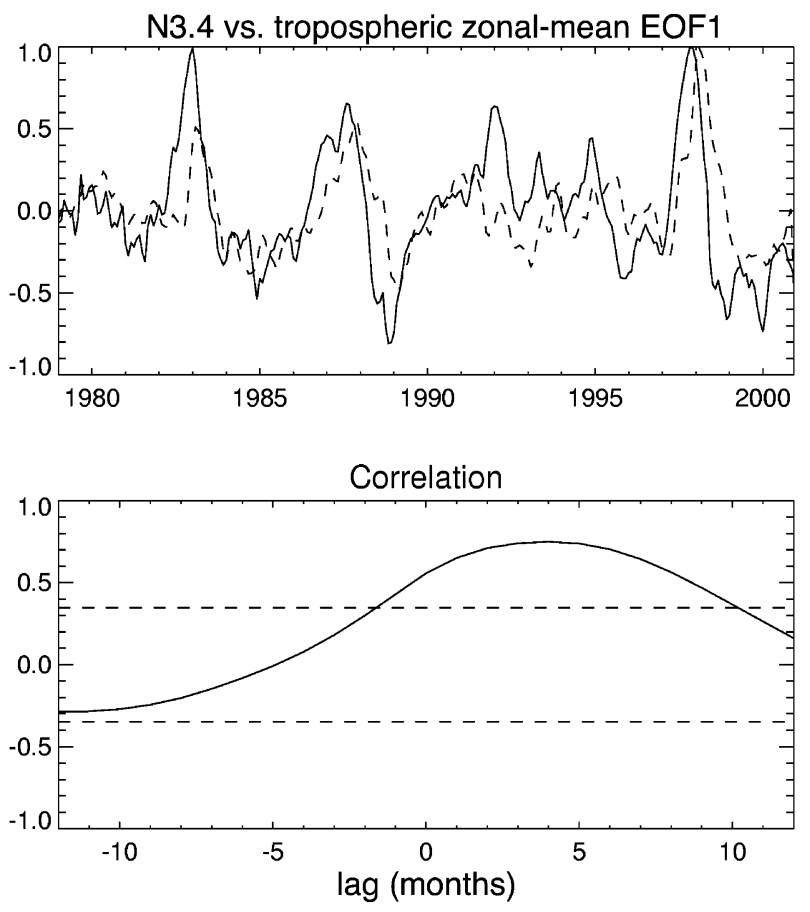

FIG. 2. (top) PC times series of the first EOF of MSU T2LT zonalmean temperature in the Tropics (solid line) and the N3.4 index (dashed line). The time series have been normalized to a maximum of one. (bottom) Lag correlation between the PC and N3.4 time series (the dashed lines denote correlations significant at the 95\% level). 


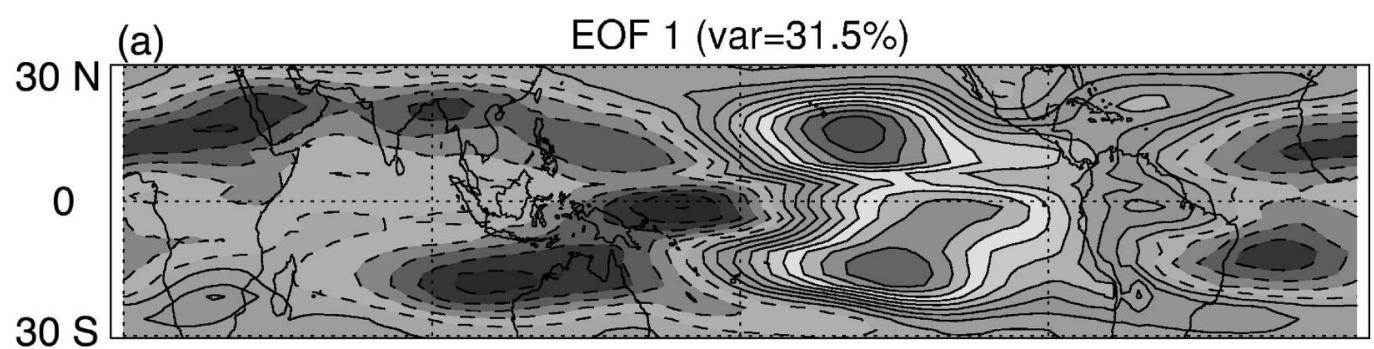

(b) $\quad$ EOF $2(\operatorname{var}=9.2 \%)$

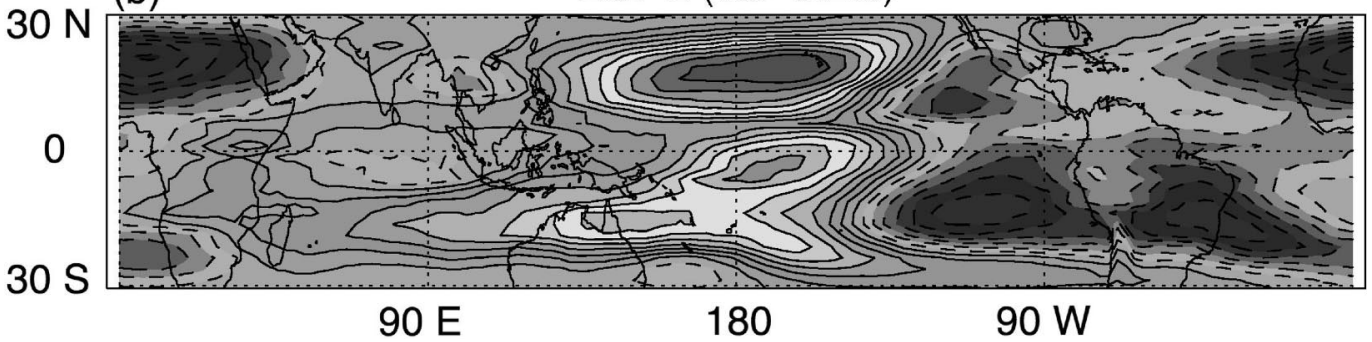

FIG. 3. As in Fig. 1 but for (a) the first and (b) second EOFs of MSU T2LT eddy temperature in the Tropics. The contour levels are arbitrary.

their composite ENSO cycle. This EOF explains a bit more than $9 \%$ of the zonally asymmetric temperature variability, and the maximum correlation between its PC and N3.4 is only about 0.5 . Nonetheless, it captures important details of the temporal evolution of tropical temperature during ENSO events, as shown next. Note that the two eddy EOFs, plus zonal-mean [EOF1], together explain $40 \times 44+89 \times 56=68 \%$ of the variance of the temperature field in the tropical troposphere (cf. Table 1).

Figure 5 shows Hovmöller diagrams (longitude versus time) of MSU temperatures averaged over the latitude range $\left(25^{\circ} \mathrm{S}-25^{\circ} \mathrm{N}\right)$ and their reconstruction in terms of the zonal-mean and eddy EOFs. The MSU data are shown in Fig. 5a, while their reconstruction in terms of [EOF1], EOF1*, and EOF2* is shown in Fig. 5b. The reconstruction compares quite well with the data, capturing the main features of every warm ENSO event in the period of analysis, as well as a minor but important feature, namely, the early appearance of warm anomalies near the date line. Both the data and the reconstruction indicate that tropical warming associated with an El Niño event does not occur simultaneously at all longitudes; instead, warm anomalies appear in temperatures of the middle troposphere near the date line several months before the strongest signal develops in the eastern Pacific. Only in the later stages of the events do warm anomalies spread in a more nearly zonally uniform pattern across the entire tropical belt.

In terms of EOFs, ENSO-related temperature anomalies occur initially as wave patterns, which both precede the full development of tropical SST anomalies (EOF2*) and develop simultaneously with them (EOF1*). YW94 (see their Fig. 10) have demonstrated that wavelike temperature anomalies are very strongly correlated with anomalies in outgoing longwave radiation (which is a proxy for tropical convective heating). Thus, a natural interpretation of our eddy EOFs is that they represent the equatorial wave response to anomalous latent heat release. On the other hand, the zonally symmetric component of atmospheric warming ([EOF1]) lags the development of the SST anomalies and is probably best interpreted as a diabatic response to changes in the surface energy balance during ENSO, as suggested by YW94 and Trenberth et al. (2002).

It is worth pointing out that none of the leading EOFs of MSU T2LT data reflect the impact of volcanic eruptions on tropical tropospheric temperature. Our EOF analysis does identify such an effect, but only in the second zonal-mean EOF ([EOF2]; not shown), which captures a rather small fraction of the tropical temperature variance $(6 \%$ of the zonal mean, or about $3 \%$ of the total; see Table 1). Atmospheric optical depth (AOD) data based on the work of Sato et al. (1993) were obtained from the Stratospheric Processes and their Role in Climate (SPARC) Data Center (www.sparc.sunysb. edu) and, after averaging globally, were correlated with the PC of tropospheric [EOF2]. The correlation, shown in Fig. 6a, is significant for lags near zero because of the strong cooling that accompanies the increase in AOD following the eruptions of El Chichón and Mount Pinatubo. This result appears to be at odds with the finding of Michaels and Knappenberger (2000) that the effect of volcanic aerosols is an important predictor of globalmean tropospheric temperature. However, the discrepancy is likely due to the emphasis of our analysis on tropical variability, which is dominated by ENSO. 
(a) N3.4 vs. tropospheric eddy EOF1
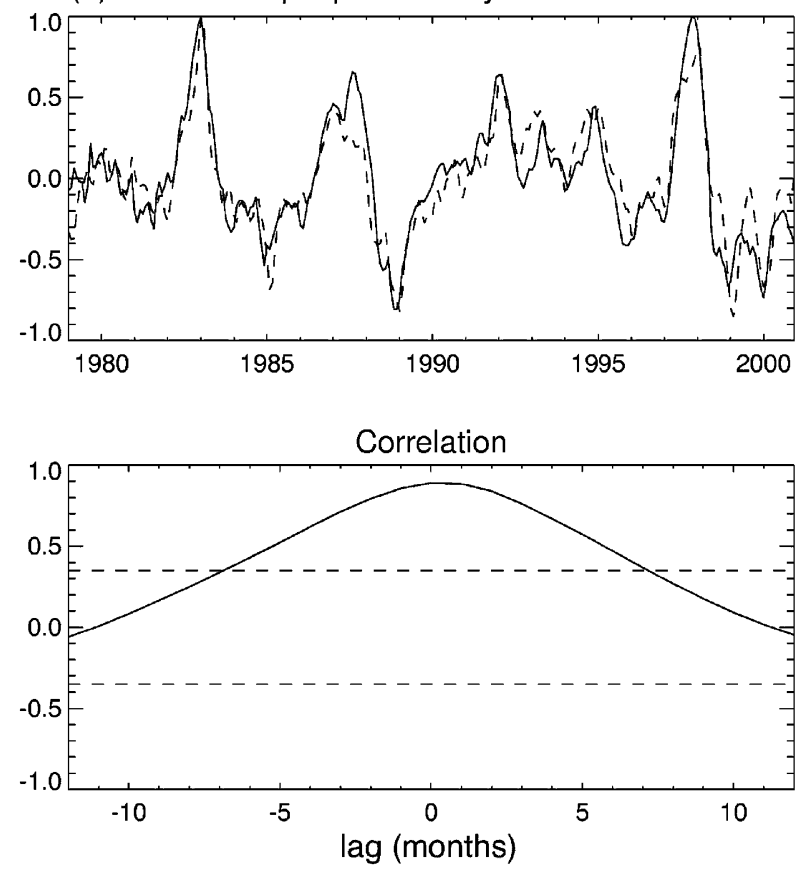

(b) N3.4 vs. tropospheric eddy EOF2
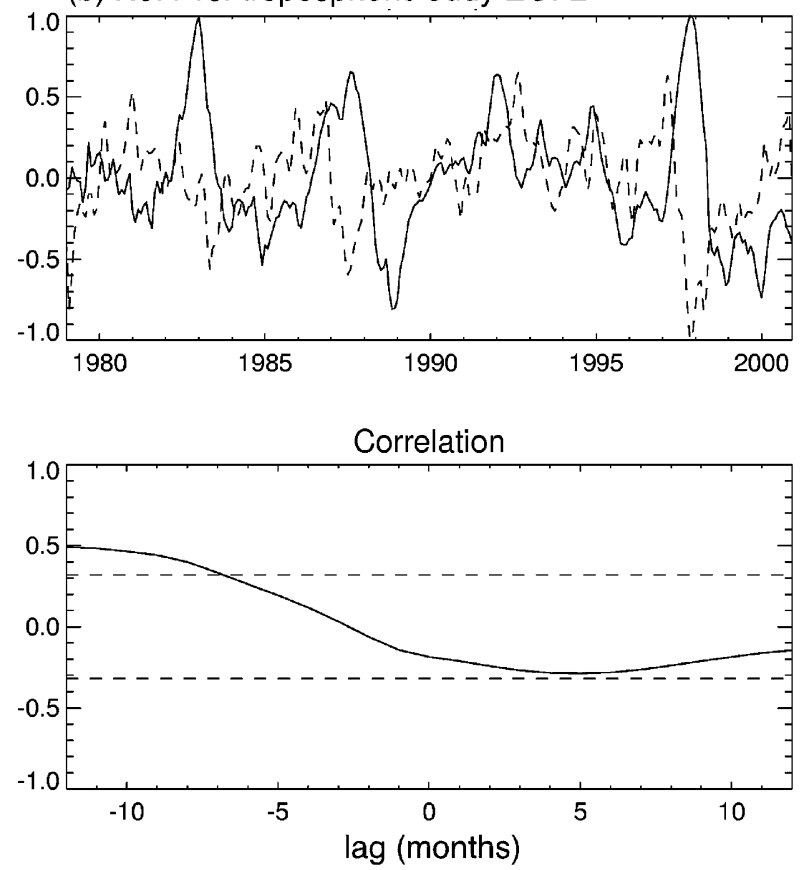

FIG. 4. As in Fig. 2 but for the PCs of (a) the first and (b) second EOFs of MSU T2LT eddy temperature in the Tropics vs N3.4.

\section{b. The tropical stratosphere}

The first two zonal-mean EOFs of tropical stratospheric temperature are shown in Fig. 7. They account for $87 \%$ and $11 \%$ of the zonal-mean temperature variance in the tropical lower stratosphere. The zonal-mean variance itself constitutes $89 \%$ of the total, so the two
EOFs capture a remarkable $98 \times 89=87 \%$ of the total variance of MSU T4 data in the Tropics (Table 2 summarizes the distribution of tropical $\mathrm{T} 4$ variance). The PC series of stratospheric [EOF1] (Fig. 8a) contains a large signal associated with the volcanic eruptions of El Chichón (1982) and Mount Pinatubo (1991), which are indicated by carets on the abscissa of the figure. Note, however, that a substantial fraction of the variance in this PC is not related to these two events and must be driven by other processes, such as adiabatic cooling or warming due to variability in the Brewer-Dobson circulation (Randel et al. 2002). This can be appreciated from Fig. 6b, which shows the correlation between the PC of stratospheric [EOF1] and the optical depth index, AOD. The stratospheric warming following the two large volcanic eruptions is readily apparent, and drives the correlation above the $95 \%$ significance level; however, aside from these two events, there is little correspondence between the PC of [EOF1] and AOD.

The PC series of the stratospheric [EOF2] (Fig. 8b) is very strongly correlated ( $r=0.83$ at lag $1-2$ months; not shown) with the $30-\mathrm{mb}$ zonal wind at Singapore, a conventional index of the stratospheric quasi-biennial oscillation (QBO). This pattern of variability, which was also identified by YW94, has a meridional structure consistent with that of the QBO, with a lobe straddling the equator flanked to the north and south by lobes of opposite sign (see Fig. 7b). Thus, it is clear that [EOF2] represents lower-stratospheric variance associated with the descending QBO. [EOF2] contributes $11 \times 89=$ $10 \%$ to the total temperature variance in the lower tropical stratosphere. At first glance this value appears to be inconsistent with Yulaeva and Wallace's remark that, after removing the effects of volcanic eruptions, the QBO signal accounts for $42 \%$ of the variance in MSU tropical lower-stratospheric temperature for the period 1979-91. However, YW94 subtracted the tropical-mean temperature averaged between $20^{\circ} \mathrm{S}$ and $20^{\circ} \mathrm{N}$ in an effort to suppress the effects of volcanic signals in their analysis. This procedure, which turns out to be unnecessary, has the effect of eliminating essentially all the variability associated with our [EOF1], which has a broad meridional structure (and contributes over $77 \%$ of the total variance in T4; cf. Fig. 9a and Table 2). If this contribution is removed, the percentage of variance associated with [EOF2] rises to about $43 \%$, in excellent agreement with YW94.

The PCs of both [EOF1] and [EOF2] are uncorrelated with N3.4 (not shown). However, stratospheric eddy variability is strongly correlated with ENSO. Figure 9 shows the first two EOFs of the eddy temperature field in the tropical lower stratosphere. These EOFs capture the majority of the zonally asymmetric variability: $49 \%$ and $11 \%$, respectively, and their correlations with N3.4 (not shown) are highly significant. Moreover, comparison of Figs. 9 and 3 reveals that the stratospheric eddy EOFs are nearly mirror images of their tropospheric counterparts (which are also ENSO-related, as shown 
(a)

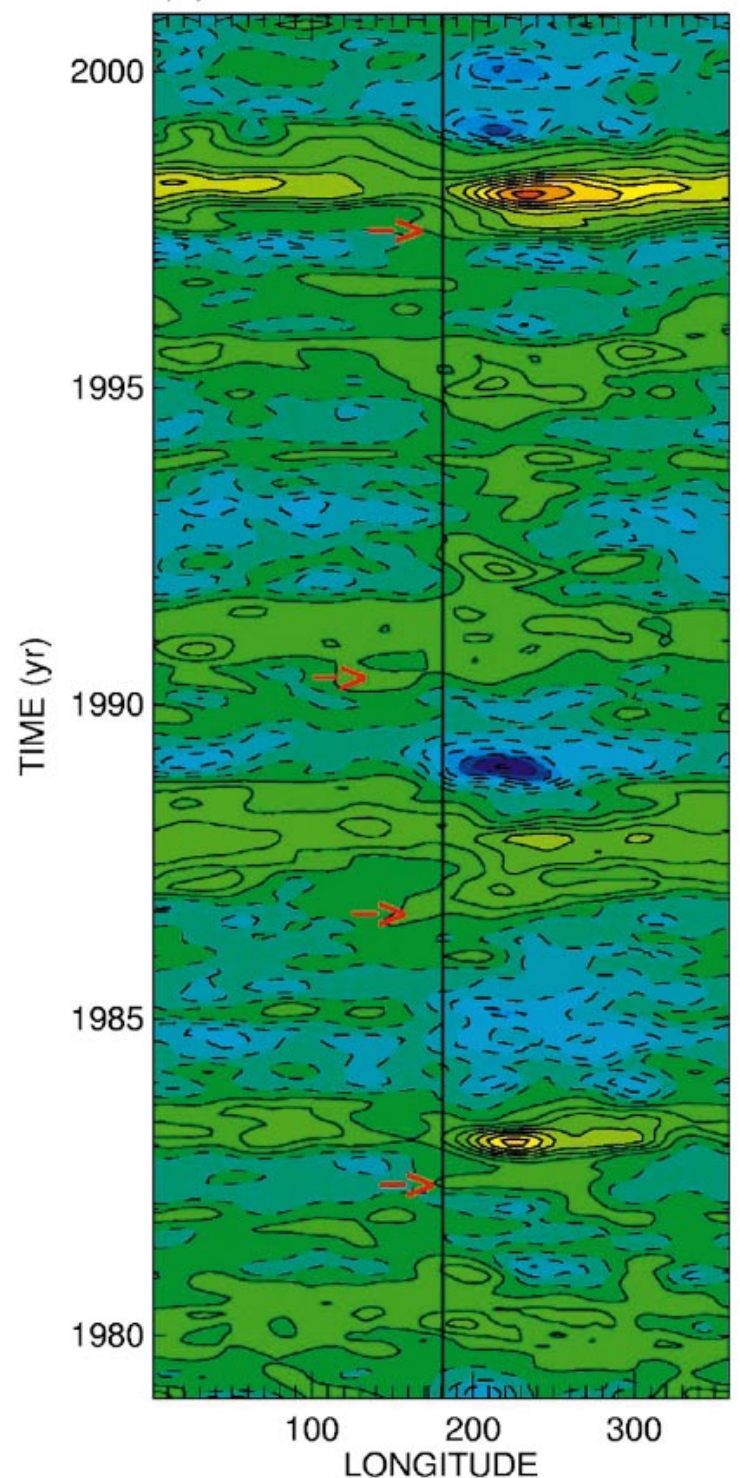

(b)

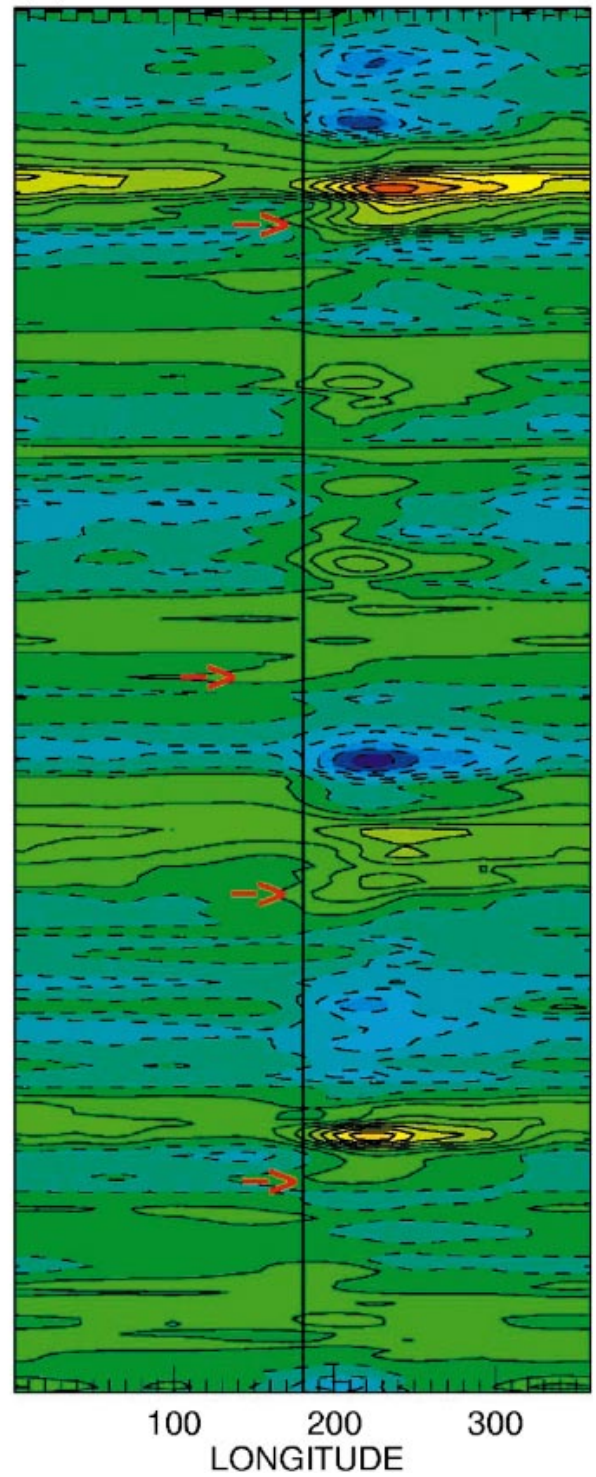

FIG. 5. (a) Hovmöller diagram of MSU T2LT temperatures averaged over $\pm 25^{\circ}$; (b) reconstruction of (a) using [EOF1], EOF1*, and EOF2* of MSU T2LT data. The contour interval is $0.2 \mathrm{~K}$; negative contours are dashed, and the first solid contour is zero. The arrows point to the occurrence of warm anomalies near the date line before the development of peak warm anomalies in the eastern Pacific. (See text for details.)

previously). This suggests that each pair of eddy EOFs reflects the behavior of an internal equatorial wave, or wave packet, having opposite phase in temperature in the middle troposphere and lower stratosphere (see, e.g., Gill 1980; Geisler 1981; Garcia and Salby 1987; Horinouchi and Yoden 1996). The conclusion is reinforced by Fig. 10, which shows that the PCs of tropospheric and stratospheric EOF1* are almost perfectly correlated at zero lag, and those of tropospheric and stratospheric EOF2* are very highly correlated.

As one would expect from the foregoing discussion, the PCs of stratospheric EOF1* and EOF2* are uncorrelated with those of stratospheric [EOF1] and [EOF2].
Thus, our analysis indicates that the stratospheric signal of ENSO operates independently of variability associated with volcanic eruptions or the QBO and is purely a wave phenomenon, the upper-air manifestation of internal equatorial waves forced in the troposphere by the anomalous convection that accompanies changes in tropical SST. There is no indication in the MSU data of a zonalmean ENSO signal like that seen in the troposphere.

\section{The extratropical signal of ENSO}

The foregoing analysis has dealt only with the tropical ENSO signal, since that is all that can be reconstructed 
(a) AOD vs. tropospheric zonal-mean EOF2
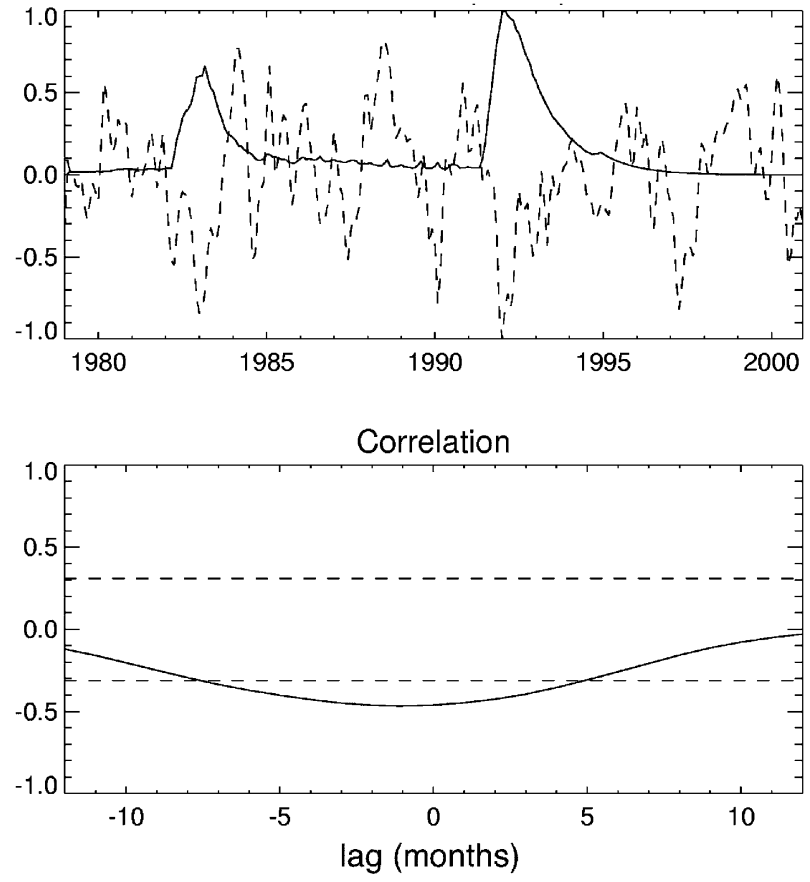

(b) AOD vs. stratospheric zonal-mean EOF1

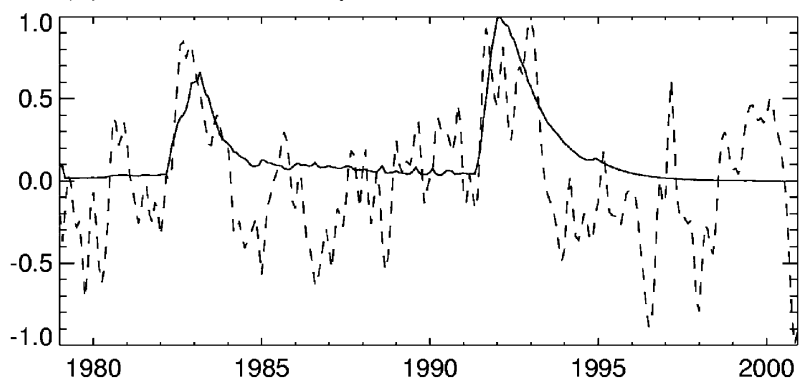

Correlation

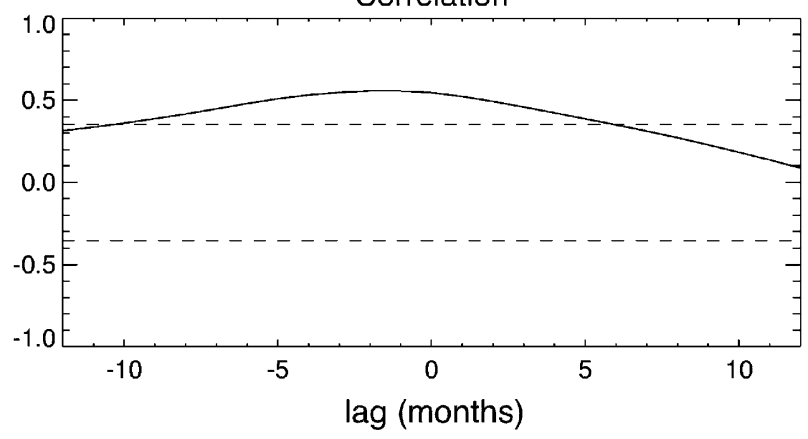

FIG. 6. As in Fig. 2 but for (a) the PC of tropospheric [EOF2] vs $\mathrm{AOD}$, and (b) the PC of stratospheric [EOF1] vs AOD.

directly when EOFs are derived from MSU data windowed by the function (1). However, an estimate of the signal of ENSO in extratropical temperatures may be obtained by regressing the MSU data onto the PCs of the EOFs related to N3.4 index. Since they are well
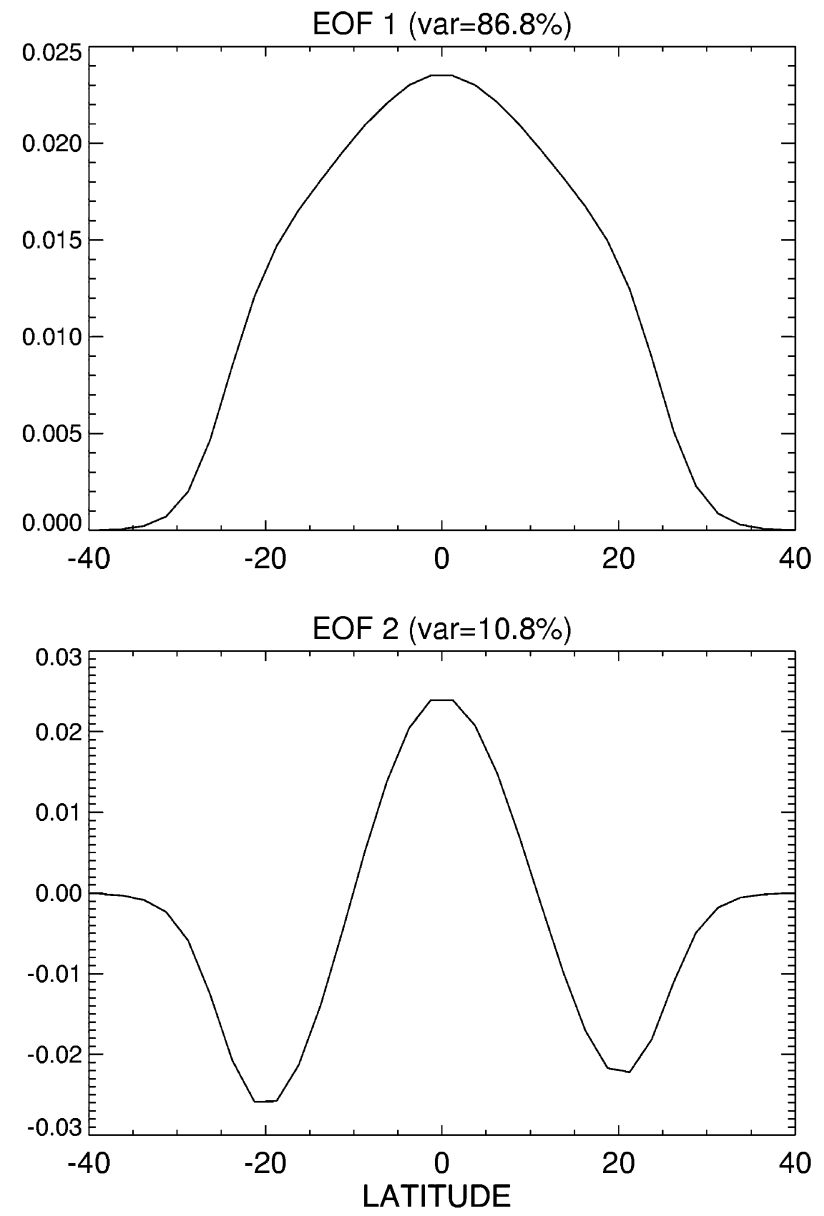

FIG. 7. As in Fig. 1 but for the first and second EOFs of MSU T4 zonal-mean temperature in the Tropics.

correlated with N3.4 index at different lags, we may expect that multiple regression onto the PCs will capture a greater fraction of the extratropical variance associated with ENSO than regression onto a single index series like N3.4.

We calculate regressions for the global MSU data as follows: For the troposphere, we regress the zonal-mean component of MSU T2LT data onto the PC of tropospheric [EOF1], and the eddy component of T2LT onto the PCs of tropospheric EOF1* and EOF2*. For the stratosphere, we have seen above that the ENSO signal

TABle 2. Distribution of MSU T4 variance in the Tropics.

\begin{tabular}{lccc}
\hline \hline & $\begin{array}{c}\text { Zonal-mean } T \\
(\%)\end{array}$ & Eddy $T(\%)$ & Total $T(\%)$ \\
\hline Zonal mean & 100 & - & 89 \\
[EOF1] & 87 & - & 77 \\
[EOF2] & 11 & - & 10 \\
Eddies & - & 100 & 11 \\
EOF1*a & - & 49 & $5^{\mathrm{a}}$ \\
EOF2*a & - & 11 & $1^{\mathrm{a}}$ \\
\hline
\end{tabular}

${ }^{a}$ EOFs and variance associated with ENSO. 

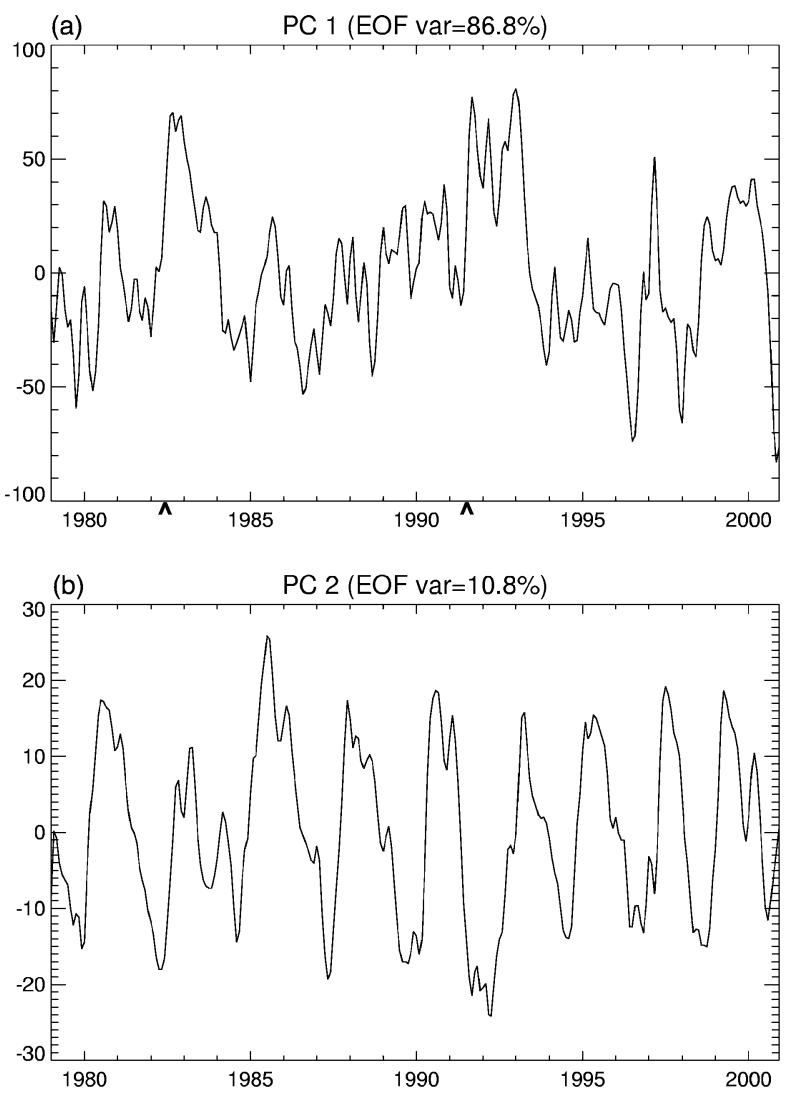

FIG. 8. PCs of (a) the first and (b) second zonal-mean EOFs of MSU T4 temperature in the Tropics. The amplitude scale is arbitrary. The first PC (a) attains large amplitudes following the eruptions of El Chichón and Mount Pinatubo, identified by carets on the time axis. The second PC (b) is very highly correlated with the stratospheric QBO. (See text for details.) is associated only with the EOFs of the eddy field, so we regress the eddy component of MSU T4 data onto the PCs of stratospheric EOF1* and EOF2*. The resulting, standardized regression coefficients are defined at all latitude and longitude points on the MSU grid, forming regression matrices that can be used together with the standardized PC series to reconstruct the global ENSO signal; that is,

$$
\begin{aligned}
& \hat{T}_{2 \mathrm{LT}}(\lambda, \theta ; t)= {[\mathbf{M}]_{1 \mathrm{~T}}(\lambda, \theta) \times[\mathrm{PC}]_{1 \mathrm{~T}}(t) } \\
&+\mathbf{M}_{1 \mathrm{~T}}^{*}(\lambda, \theta) \times \mathrm{PC}_{1 \mathrm{~T}}^{*}(t) \\
&+\mathbf{M}_{2 \mathrm{~T}}^{*}(\lambda, \theta) \times \mathrm{PC}_{2 \mathrm{~T}}^{*}(t) \\
& \hat{T}_{4}^{*}(\lambda, \theta ; t)=[\mathbf{M}]_{1 \mathrm{~S}}(\lambda, \theta) \times\left[\mathrm{PC}_{1 \mathrm{~S}}(t)\right. \\
& \\
&+\mathbf{M}_{2 \mathrm{~S}}^{*}(\lambda, \theta) \times \mathrm{PC}_{2 \mathrm{~S}}^{*}(t),
\end{aligned}
$$

where $\hat{T}_{2 \mathrm{LT}}$ and $\hat{T}_{4}^{*}$ are the regression estimates of MSU T2LT (total) and T4 (eddy) temperature fields; $\mathbf{M}$ are regression matrices and $\mathrm{PCs}$ are the principal component time series; brackets and asterisks denote zonal-mean and eddy quantities, respectively; the subscripts $\mathrm{T}$ and $S$ refer to the troposphere and stratosphere; and the subscripts 1 and 2 denote regressions on the PCs of the first and second EOFs.

The regression matrices are statistically significant over large regions of the Tropics. In extratropical latitudes, the regression matrix for the zonal-mean PC of the troposphere, $[\mathbf{M}]_{1 \mathrm{~T}}$, is generally not significant, but the regression on the eddy PCs is highly significant over large regions. In the troposphere, these significant regions resemble wave trains, while in the stratosphere they take on the shape of a planetary-scale anomaly. Of course, in the Tropics the regressions (3) account for
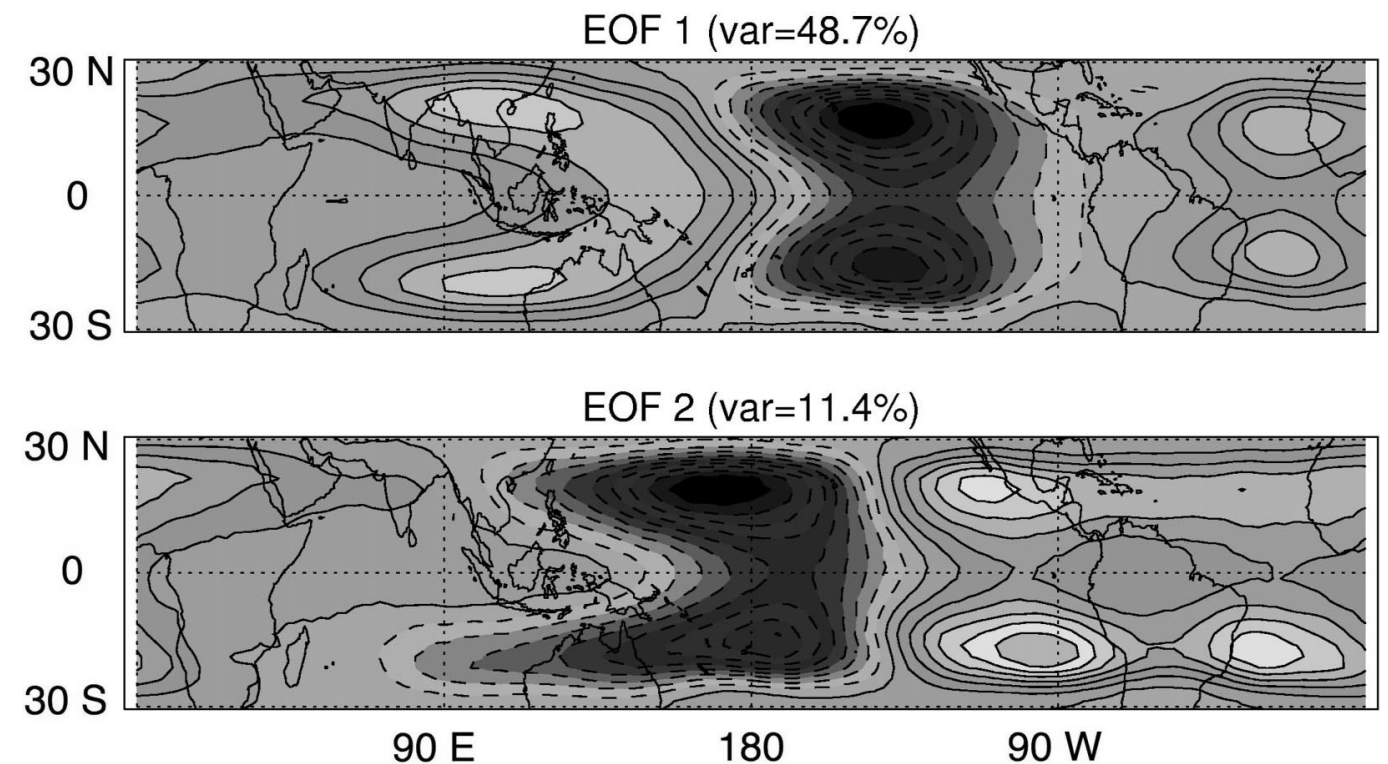

FIG. 9. As in Fig. 1 but for (top) the first and (bottom) second EOFs of MSU T4 eddy temperature. The contour levels are arbitrary. Note that the patterns are nearly mirror images of the EOFs shown in Fig. 3. 
(a) tropospheric EOF1' vs. stratospheric EOF1'
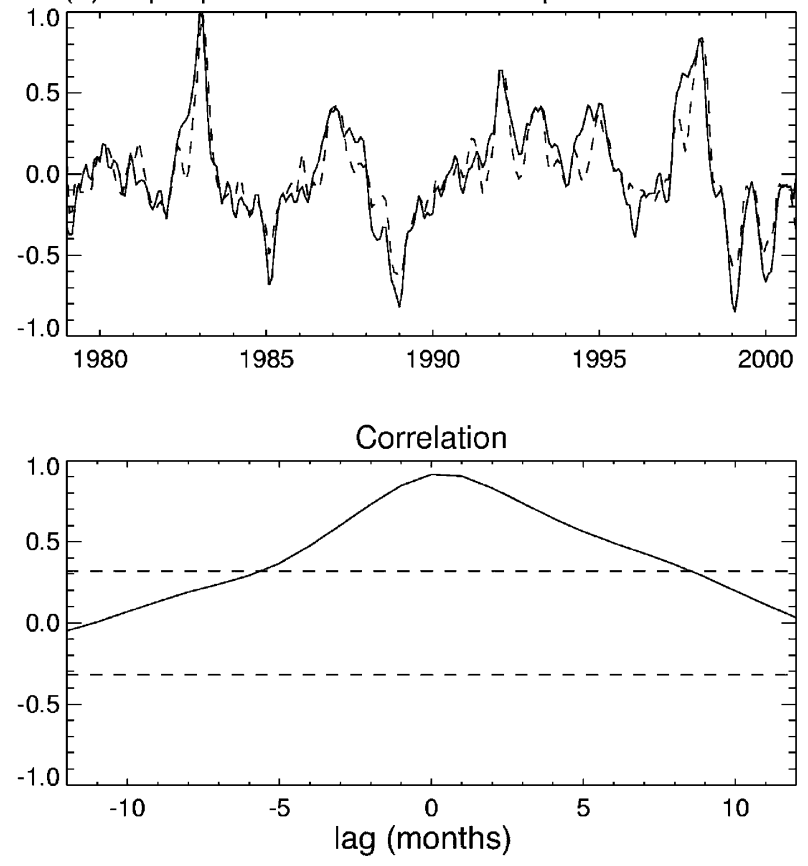

(b) tropospheric EOF2' vs. stratospheric EOF2'
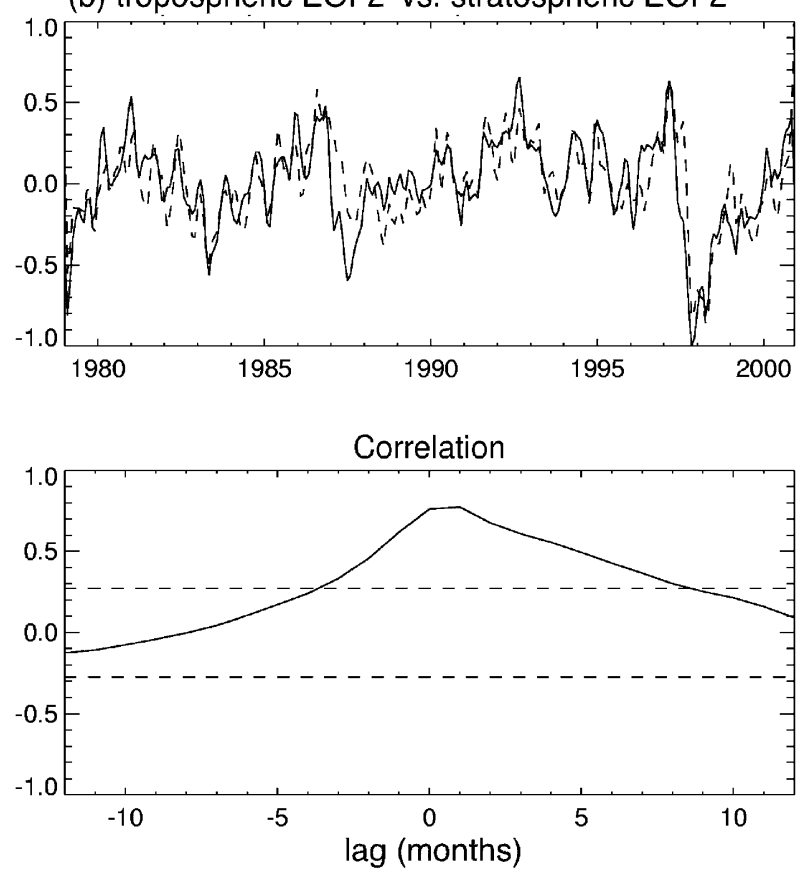

FIG. 10. (a) PC series of the first EOF of MSU T2LT (solid) and T4 (dashed) eddy temperature, and their lag correlation. The dashed lines denote correlations significant at the 95\% level. (b) As in (a) but for the PCs of the second EOFs.

the same large percentage of the variances as the EOFs discussed in section 3 (68\% of the total tropospheric variance and $60 \%$ of the eddy stratospheric variance; cf. Tables 1 and 2). As expected, these values are considerably larger than those obtained by regressing onto a single time series. For example, regressions of T2LT and T4 data onto N3.4, account for only $27 \%$ of the total tropospheric variance and $33 \%$ of the eddy stratospheric variance. In extratropical regions, the variance captured by (3) is a much smaller percentage of the total: less than $10 \%$, in both the troposphere and stratosphere. Evidently, most of the variance outside the Tropics is not linearly related to ENSO; in addition, ENSO affects the extratropics preferentially in local winter, when the strongest teleconnections occur between the tropical Pacific and higher latitudes.

As a specific example, Figs. 11 and 12 show reconstructions of MSU global temperatures compared with the original data for January 1998 (i.e., near the peak of the 1997-98 ENSO event as measured by N3.4). In the troposphere (see Fig. 11), the agreement is excellent in the Tropics and subtropics, capturing much of the fine detail of the data, in particular the strong warm anomaly in the eastern Pacific and the more zonally homogeneous behavior at other longitudes. At higher latitudes, the reconstruction is best in regions east and poleward of the tropical eastern Pacific, where largeamplitude wave trains are seen to extend into middle latitudes (although the reconstruction underestimates their amplitude). These so-called Pacific-North America (PNA) and Pacific-South America (PSA) patterns are known to be among the more robust features of the extratropical signal of ENSO, and have been interpreted as Rossby wave trains that propagate poleward and eastward from regions of anomalous convective forcing in the tropical Pacific (e.g., Wallace and Gutzler 1981; Horel and Wallace 1981; Hoskins and Karoly 1981; Garcia and Salby 1987; Lau et al. 1994).

In the stratosphere (Fig. 12) the reconstruction also agrees well with the original data in the Tropics; elsewhere, the position and sign of the temperature anomalies are in good agreement, but the amplitude is smaller in the reconstruction, especially at high latitudes of the Northern Hemisphere. The cold anomalies in the tropical eastern Pacific overlie warm anomalies in the tropospheric response (Fig. 11), supporting the interpretation of these patterns as a single physical entity, that is, an equatorial Rossby wave. In contrast to the troposphere, the extratropical response is no longer a wave train but consists mainly of a large-amplitude anomaly of zonal wavenumber 1 , which is strongest in the winter hemisphere. This is consistent with theoretical expectations (Charney and Drazin 1961, etc.), which predict that only the largest scale quasi-stationary Rossby waves are able to propagate into the stratosphere, and then only in winter, when stratospheric winds are westerly.

It should be noted that the reconstructions of the temperature fields for January 1998 are quite good, probably because the very large ENSO event of 1997-98 has a strong influence on the calculated regression matrices. Nonetheless, this example is not atypical, and it is representative in that tropical temperatures are always more faithfully reconstructed than the extratropical field. 


\section{(a) T2LT data for January 1998}

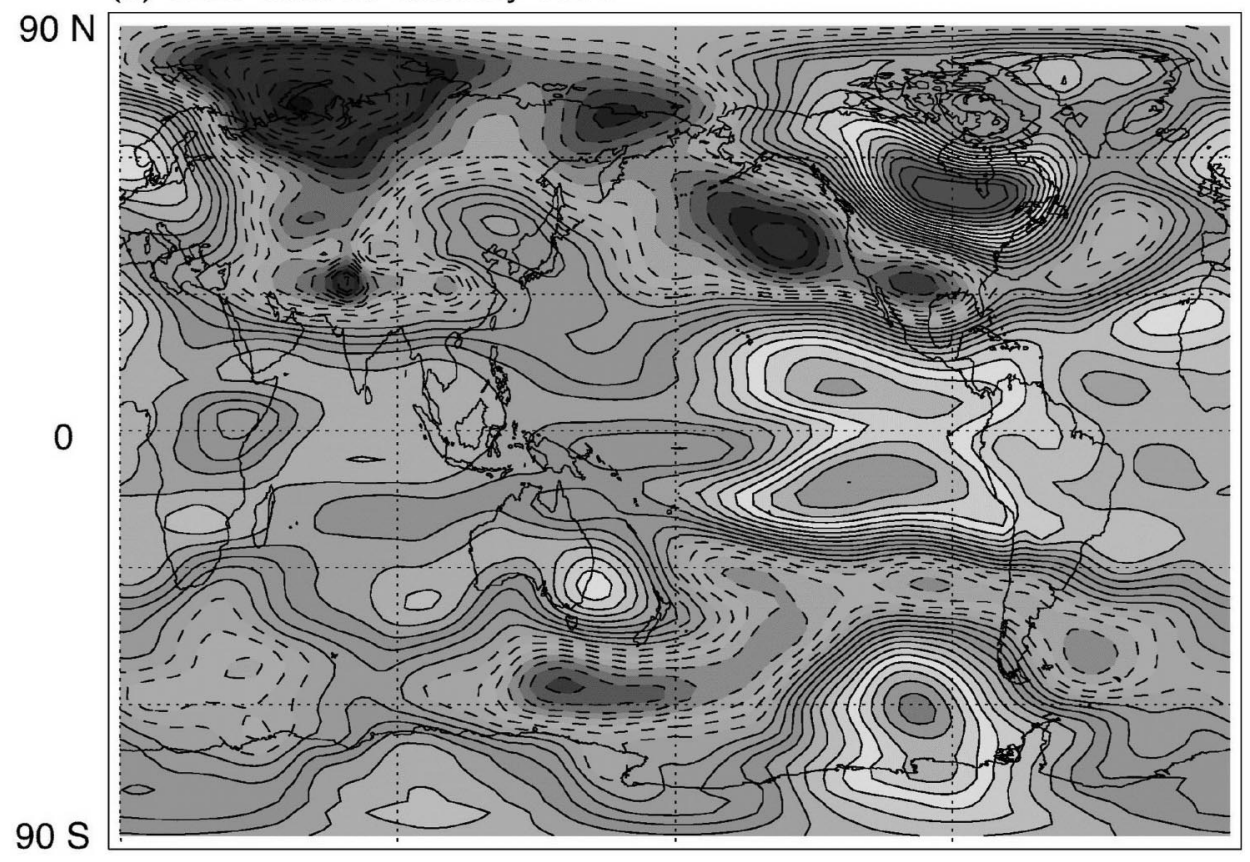

\section{(b) Reconstruction}

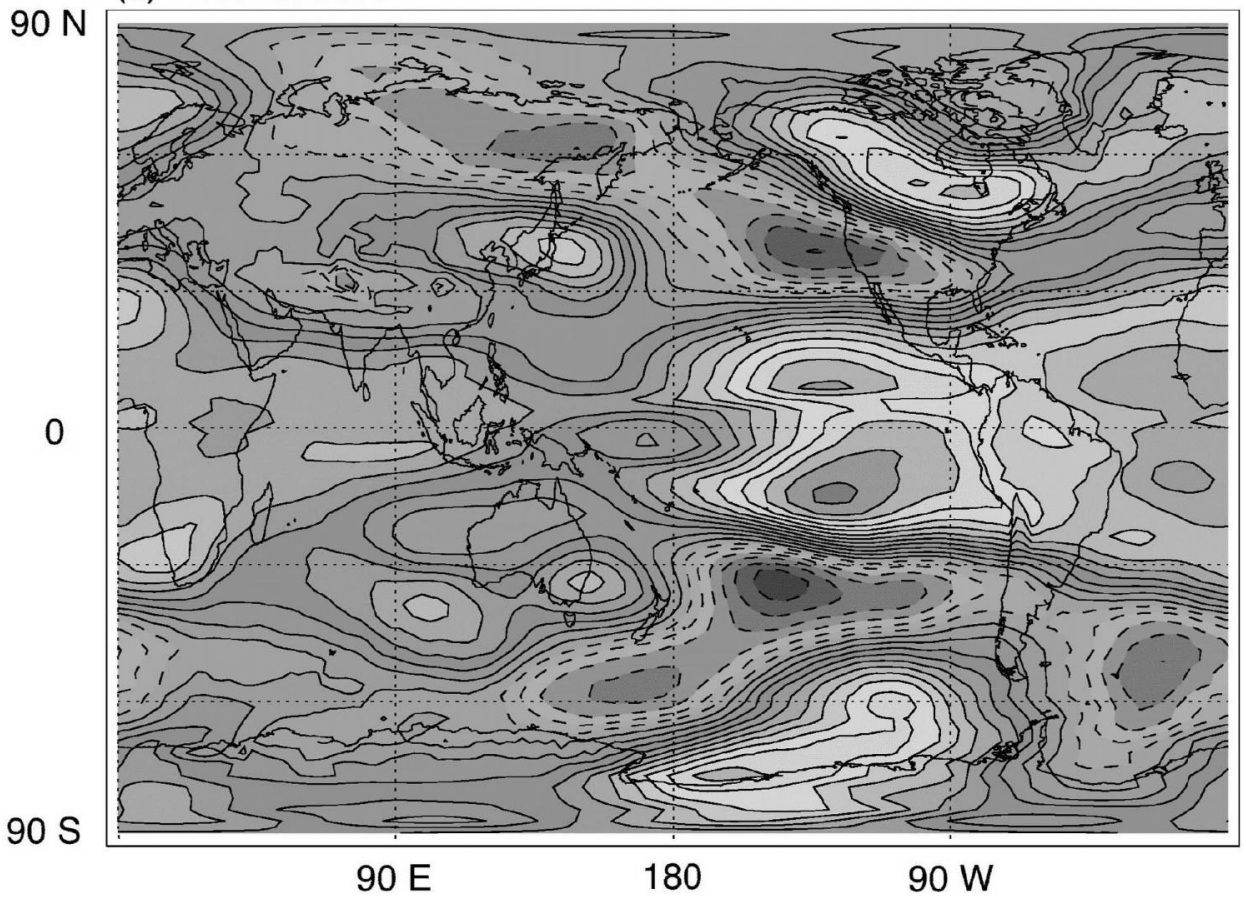

FIG. 11. (a) MSU T2LT global temperature field for Jan 1998; (b) reconstruction of (a) using the multiple regression (3). The contour interval is $0.2 \mathrm{~K}$; negative contours are dashed, and the first solid contour is zero. (See text for details.)

\section{Summary}

The ENSO signal in tropospheric and lower-stratospheric temperatures observed by various microwave sounding unit instruments has been analyzed for the period 1979-2000. These data provide the coverage and spatial resolution needed to develop a comprehensive, quantitative description of the impact of ENSO on tropospheric and lower-stratospheric temperatures. In the 
(a) T4 data for Januarv. 1998

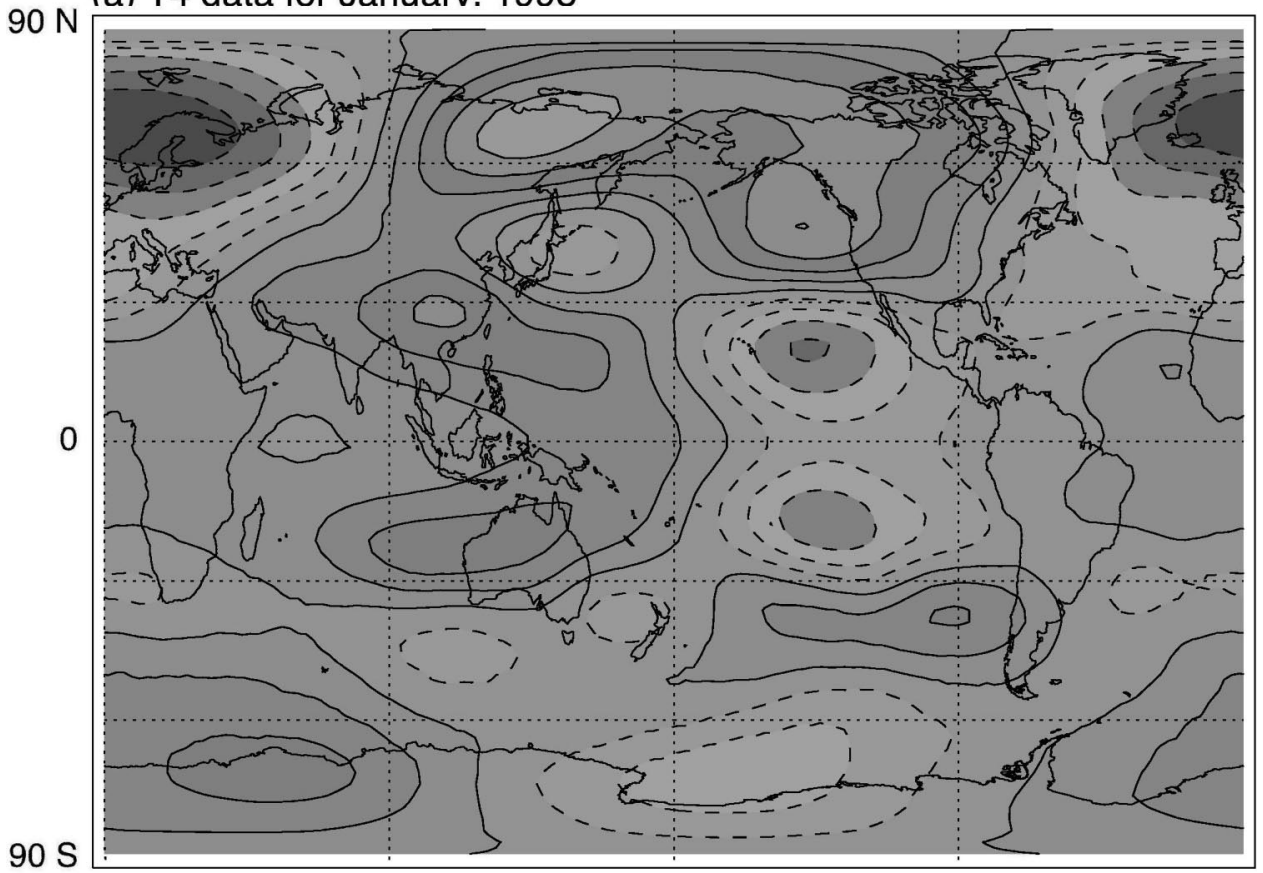

(b) Reconstruction

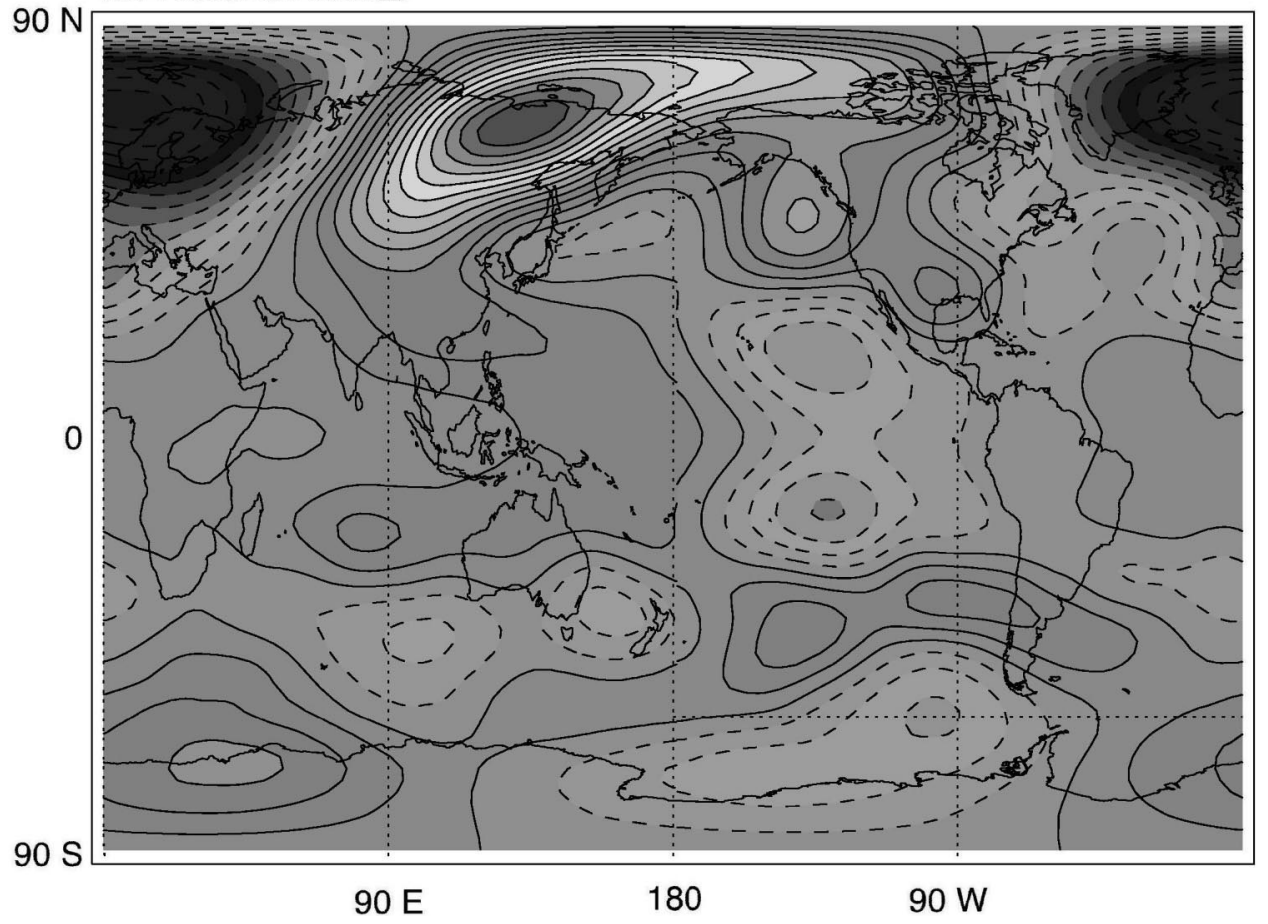

FIG. 12. As in Fig. 11 but for MSU T4 temperature and with a contour interval of $0.4 \mathrm{~K}$.

Tropics, MSU data from the T2LT and T4 channels have been represented in terms of separate EOFs for zonalmean and eddy temperatures. This approach leads to a compact, physically intuitive representation of the data that shows clearly the evolution of zonal-mean and wavelike signals in the Tropics. The extratropical signal of ENSO was estimated by regressing the MSU data on the PCs of the tropical EOFs. Our findings can be summarized as follows:

1) In the tropical troposphere, ENSO is the main source of variability; three EOFs correlated with the Niño- 
3.4 (N3.4) SST index explain $68 \%$ of the total tropical variance in the troposphere (cf. Table 1). The EOFs represent three distinct patterns. The first is a zonal-mean pattern that accounts for about $50 \%$ of the variance; it corresponds to the warming that develops throughout the tropical troposphere during the mature phase of warm ENSO events, and it lags N3.4 by 3-4 months. The remaining ENSO variability (18\% of the total) is captured by two zonally asymmetric patterns: one in phase with N3.4 and another, centered near the date line, which leads N3.4 by 1012 months. The second and first eddy EOFs may be identified with the precursor phase of ENSO events (cf. Rasmusson and Carpenter 1982), and with the mature response in the eastern Pacific, respectively. Incidentally, volcanic eruptions are responsible for only a small fraction of the variability in the tropical troposphere; their influence is captured by a second zonal-mean EOF that explains about $3 \%$ of the total variance in this region.

2) In the tropical lower stratosphere, ENSO is not a major source of variability. Fully $77 \%$ of the total variance in this region is explained by a zonal-mean EOF with broad latitudinal structure that is strongly influenced by the eruptions of El Chichón and Mount Pinatubo, plus a second zonal-mean EOF that accounts for $10 \%$ of the total variance, and whose latitudinal structure and PC time series are closely related to the behavior of the QBO (cf. Table 2). The influence of the QBO (van Loon and Labitzke 1987; Xu 1992; Hamilton 1993; Baldwin and O'Sullivan 1995) and volcanic eruptions (Spencer and Christy 1993; Christy and Drouilhet 1994) on the lower stratosphere has been studied previously, but no clear relationship between them and ENSO has been established. Our zonal-mean EOFs in the stratosphere are uncorrelated with $\mathrm{N} 3.4$, implying that volcanic eruptions and the QBO operate independently of ENSO in MSU data for the period 1979-2000. In fact, in the tropical lower stratosphere, the ENSO signal is purely wavelike and mirrors the behavior in the troposphere. Two stratospheric eddy EOFs account for $60 \%$ of the zonally asymmetric variance (but only $\sim 6 \%$ of the total variance; see Table 2 ), and are almost perfectly correlated with the tropospheric eddy EOFs.

3) The eddy EOFs in the tropical troposphere and lower stratosphere can be interpreted quite naturally as reflecting the vertical structure of equatorial waves. Although some authors (e.g., Pan and Oort 1983; Reid et al. 1989) have suggested an enhancement of the Hadley cell to explain the out-of-phase behavior of stratospheric and tropospheric signals, our results show unambiguously that the antiphase behavior does not occur in the zonal mean, as would be expected for the Hadley circulation. The results also show that an explanation in terms of the vertical structure of equatorial waves is simpler and com- pletely consistent with MSU data. Alternatively, these wave patterns may be viewed as perturbations of the Walker circulation.

4) Outside the Tropics, our results indicate that ENSO explains less than $10 \%$ of the total variance. In the troposphere, the extratropical response to ENSO takes the form of wave trains associated with the PNA and PSA patterns; in the stratosphere, the response is characterized by a planetary-scale, wavenumber-1 anomaly, present mainly in local winter, consistent with theoretical expectations for the vertical propagation of extratropical Rossby waves.

Acknowledgments. We thank Jon Eischeid for his help in obtaining the MSU data used in this paper, and Henry Diaz, Dan Marsh, Bill Randel, and Anne Smith for discussions and suggestions on the original manuscript.

\section{REFERENCES}

Angell, J. K., 1981: Comparison of variations in atmospheric quantities with sea surface temperature variations in the equatorial eastern Pacific. Mon. Wea. Rev., 109, 230-243.

, 2000a: Tropospheric temperature variations adjusted for El Niño, 1958-1998. J. Geophys. Res., 105, 11 841-11 849.

_, 2000 b: Difference in radiosonde temperature trend for the period 1979-1998 of MSU data and the period 1959-1998 twice as long. Geophys. Res., Lett., 27, 2177-2180.

Baldwin, M. P., and D. O'Sullivan, 1995: Stratospheric effects of ENSO-related tropospheric circulation anomalies. J. Climate, 8, 649-667.

Charney, J. G., and P. G. Drazin, 1961: Propagation of planetaryscale disturbances from the lower into the upper atmosphere. $J$. Geophys. Res., 66, 83-109.

Christy, J. R., and S. J. Drouilhet, 1994: Variability in daily, zonal mean lower-stratospheric temperatures. J. Climate, 7, 106-120. , and R. T. McNider, 1994: Satellite greenhouse signal. Nature, 367, 325 .

- R. W. Spencer, and W. D. Braswell, 2000: MSU tropospheric temperatures: Dataset construction and radiosonde comparisons. J. Atmos. Oceanic Technol., 17, 1153-1170.

Diaz, H. F., M. P. Hoerling, and J. K. Eischeid, 2001: ENSO variability, teleconnections and climate change. Int. J. Climatol., 21, 1845-1862.

Garcia, R. R., and M. L. Salby, 1987: Transient response to localized episodic heating in the Tropics. Part II: Far-field behavior. $J$. Atmos. Sci., 44, 499-530.

Geisler, J. E., 1981: A linear model of the Walker circulation. J. Atmos. Sci., 38, 1390-1400.

Gill, A. E., 1980: Some simple solutions for heat-induced tropical circulation. Quart. J. Roy. Meteor. Soc., 106, 447-462.

Halpert, M. S., and C. F. Ropelewski, 1992: Surface temperature patterns associated with the Southern Oscillation. J. Climate, 5, 577-593.

Hamilton, K., 1993: An examination of observed Southern Oscillation effects in the Northern Hemisphere stratosphere. J. Atmos. Sci., 50, 3468-3473.

Horel, J. D., and J. M. Wallace, 1981: Planetary-scale atmospheric phenomena associated with the Southern Oscillation. Mon. Wea. Rev., 109, 813-829.

Horinouchi, T., and S. Yoden, 1996: Excitation of transient waves by localized episodic heating in the Tropics and their propagation into the middle atmosphere. J. Meteor. Soc. Japan, 74, 189210 .

Hoskins, B. J., and D. Karoly, 1981: The steady linear response of 
a spherical atmosphere to thermal and orographic forcing. $J$. Atmos. Sci., 38, 1179-1196.

Hurrell, J. W., S. J. Brown, K. E. Trenberth, and J. R. Christy, 2000: Comparison of tropospheric temperatures from radiosondes and satellites: 1979-98. Bull. Amer. Meteor. Soc., 81, 2165-2177.

Jones, P. D., 1989: The influences of ENSO on global temperatures. Climate Monit., 17, 80-89.

Kelly, P. M., and P. D. Jones, 1996: Removal of El Niño-Southern Oscillation signal from the gridded surface air temperature data set. J. Geophys. Res., 101, 19 013-19 022.

Kiladis, G. N., and H. F. Diaz, 1989: Global climatic anomalies associated with extremes in the Southern Oscillation. J. Climate, 2, 1069-1090.

Lau, K. M., P. J. Shen, and I. S. Kang, 1994: Multiscale low-frequency circulation modes in the global atmosphere. J. Atmos. Sci., 51, $1169-1193$

Michaels, P. J., and P. C. Knappenberger, 2000: Natural signals in the MSU lower troposphere temperature record. Geophys. Res. Lett., 27, 2905-2908.

Oort, A. H., and J. J. Yienger, 1996: Observed interannual variability in the Hadley circulation and its connection to ENSO. J. Climate, 9, 2751-2767.

Pan, Y. H., and A. H. Oort, 1983: Global climate variations connected with sea surface temperature anomalies in the eastern tropical Pacific Ocean for the 1958-73 period. Mon. Wea. Rev., 111, $1244-1258$.

Randel, W., R. R. Garcia, and F. Wu, 2002: Time-dependent upwelling in the tropical lower stratosphere estimated from the zonal-mean momentum budget. J. Atmos. Sci., 59, 2141-2152.

Rasmusson, E. M., and T. H. Carpenter, 1982: Variations in tropical sea surface temperature and surface wind fields associated with the Southern Oscillation/El Niño. Mon. Wea. Rev., 110, 354384.

Reid, G. C., K. S. Gage, and J. R. McAfee, 1989: The thermal response of the tropical atmosphere to variations in equatorial
Pacific sea surface temperature. J. Geophys. Res., 94, $14705-$ 14716.

Richman, M. B., 1986: Rotation of principal components. J. Climatol., 6, 293-335.

Sato, M., J. E. Hansen, M. P. McCormick, and J. B. Pollack, 1993: Stratospheric aerosol optical depths, 1850-1990. J. Geophys. Res., 98, 22 987-22 994.

Spencer, R. W., and J. R. Christy, 1993: Precision lower stratospheric temperature monitoring with the MSU: Technique, validation and results 1979-1991. J. Climate, 6, 1194-1204.

Trenberth, K. E., and J. M. Caron, 2000: The Southern Oscillation revisited: Sea level pressures, surface temperatures and precipitation. J. Climate, 13, 4358-4365.

,-- D. P. Stepaniak, and S. Worley, 2002: Evolution of El Niño-Southern Oscillation and global atmospheric surface temperatures. J. Geophys. Res., 107, 4065, doi:10.1029/ 2000JD000298.

van Loon, H., and K. Labitzke, 1987: The Southern Oscillation. Part $\mathrm{V}$ : The anomalies in the lower stratosphere of the Northern Hemisphere in winter and a comparison with the quasi-biennial oscillation. Mon. Wea. Rev., 115, 357-369.

von Storch, H., and F. W. Zwiers, 1999: Statistical Analysis in Climate Research. Cambridge University Press, 484 pp.

Wallace, J. M., and D. S. Gutzler, 1981: Teleconnections in the geopotential height field during the Northern Hemisphere winter Mon. Wea. Rev., 109, 784-812.

- , and F.-C. Chang, 1982: Interannual variability of the wintertime polar vortex in the Northern Hemisphere middle stratosphere. $J$ Meteor. Soc. Japan, 60, 149-155.

Xu, J., 1992: On the relationship between the stratospheric quasibiennial oscillation and the tropospheric Southern Oscillation. J. Atmos. Sci., 49, 725-734.

Yulaeva, E., and J. M. Wallace, 1994: The signature of ENSO in global temperature and precipitation fields derived from the microwave sounding unit. J. Climate, 7, 1719-1736. 